\title{
BMJ Open Is one-stop surgery for carpal tunnel syndrome safe? A retrospective long- term follow-up study in a neurosurgical unit in Copenhagen
}

\author{
Louise Møller Jørgensen,, ${ }^{1,2,3}$ Karin Piil, ${ }^{1,4}$ Asma Bashir, ${ }^{1}$ Morten Bo Larsen, ${ }^{5}$ \\ Pamela Santiago Poggenborg, ${ }^{1}$ Sebastian Bjørck, ${ }^{6}$ Kåre Fugleholm ${ }^{1}$
}

To cite: Jørgensen LM, Piil K, Bashir A, et al. Is one-stop surgery for carpal tunnel syndrome safe? A retrospective long-term followup study in a neurosurgical unit in Copenhagen. BMJ Open 2017;7:e016103. doi:10.1136/ bmjopen-2017-016103

- Prepublication history and additional material for this paper are available online. To view these files, please visit the journal online (http://dx.doi. org/10.1136/bmjopen-2017016103).

Received 25 January 2017 Revised 21 August 2017 Accepted 22 August 2017

\section{CrossMark}

${ }^{1}$ Department of Neurosurgery, University Hospital of Copenhagen, Rigshospitalet, Blegdamsvej, Denmark ${ }^{2}$ Neurobiology Research Unit, University Hospital of Copenhagen, Rigshospitalet, Blegdamsvej, Denmark ${ }^{3}$ University of Copenhagen, Faculty of Health and Medical Sciences, Blegdamsvej, Denmark

${ }^{4}$ The University Hospitals Centre for Health Research (UCSF), Department of Oncology, Blegdamsvej, Denmark ${ }^{5}$ Department of Orthopedics, Hvidovre Hospital, KettegårdAlle Denmark

${ }^{6}$ Department of Orthopedics, Slagelse Hospital, Ingemannsvej, Denmark

Correspondence to Dr Louise Møller Jørgensen; Louisemoeller@nru.dk

\section{ABSTRACT}

Objectives The aim of this study was to evaluate onestop surgery (OSS) for carpal tunnel syndrome (CTS) regarding symptom relief and patient satisfaction. OSS in our setting means only one visit to the hospital for surgery and no hospital appointments for preassessment or followup. We hypothesised that relief of symptoms with OSS is comparable with that in non-OSS patients reported in the literature.

Design This is a long-term retrospective follow-up study (56.5 months) of 1003 patients referred for CTS and discharged with or without surgery from an OSS clinic. Of the original cohort, 671 patients completed the long-term follow-up telephone interview.

Results Two-thirds of the patients were free of even minor symptoms following surgery. The symptom relief and patient satisfaction in this study were comparable with results in non-0SS patients reported in the literature.

Conclusion The implementation of a clinical pathway and OSS for the management of CTS was safe with good longterm symptom relief and high patient satisfaction.

\section{BACKGROUND}

Increasing demands on the healthcare system call for exploration of new approaches to patient management. Carpal tunnel syndrome (CTS), which is the most frequent entrapment neuropathy, with an incidence of operative treatment of $0.6-1.7$ per 1000 population with geographical variation, ${ }^{1}$ leads to a considerable symptom burden and substantial direct and indirect medical and socioeconomic costs. ${ }^{2}$ One-stop surgery (OSS) may reduce three hospital visits (surgical preassessment, surgery and follow-up) to a single visit. Hence, OSS has a potential to improve patient satisfaction and make the use of healthcare resources more efficient. ${ }^{34}$

Potential challenges with OSS include late consent from the patient and wasted theatre time in case of same day cancellation. ${ }^{3}$ Another concern is that OSS can be associated with a substandard preassessment and
Strengths and limitations of this study

- The study includes a large number of patients.

- The follow-up also includes patients discharged without surgery from the one-stop surgery clinic.

- All data were collected retrospectively.

- A recognised patient-reported outcome measure for carpal tunnel syndrome was not used.

that this may cause poor patient selection and worse outcome.

The aim of the present study is to evaluate the long-term symptom relief in a large population of patients referred for operative treatment of CTS in a neurosurgical department in Copenhagen. We hypothesise that OSS for CTS is safe and has a comparable outcome with that of non-OSS patients reported in the literature.

Previous studies of OSS for CTS, in highly preselected patients, reported a high quality outcome and patient satisfaction. ${ }^{3-5}$ One study also included a same-day nerve conduction study in the OSS patient management. ${ }^{4}$

\section{MATERIAL AND METHODS \\ Study design}

This is a retrospective long-term follow-up study of 1003 patients discharged with or without CTS surgery from the neurosurgical OSS clinic from 2003 to 2009. Data were retrieved from patient files, and a team of two medical students and three medical doctors conducted long-term follow-up telephone interviews. Patients were excluded from the telephone interview follow-up if they were not able to understand Danish or English, had significant cognitive and/or hearing impairment or had emigrated from Denmark.

The study was approved by the Data Protection Agency j.nr. 2011-41-6315, and 


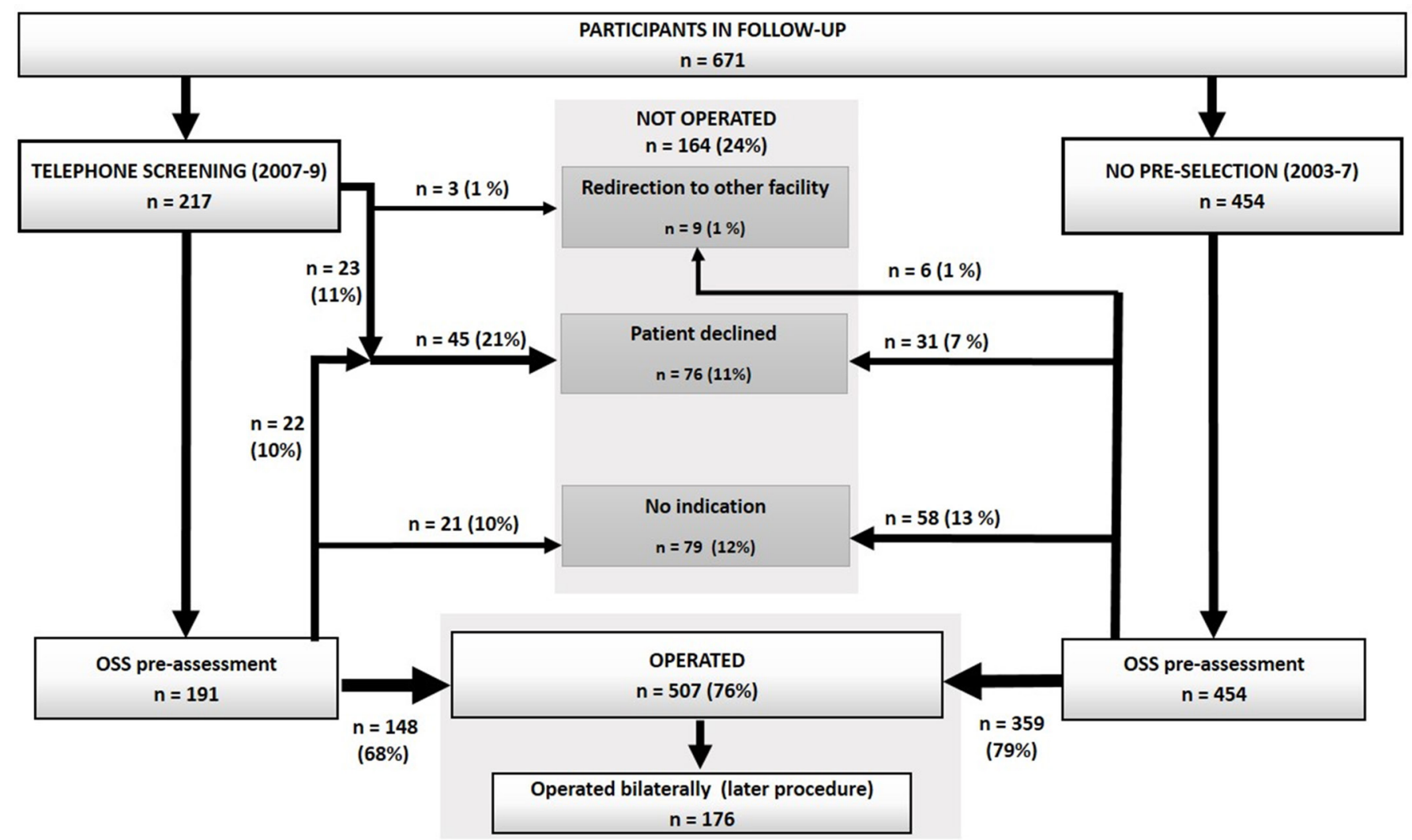

Figure 1 Flow chart of all referred patients $(n=671)$ participating in the follow-up study. The patient was discharged from the clinic without surgery for the following reasons: (1) redirection to another surgical facility, (2) patient declined surgery and (3) the surgeon did not find an indication to perform carpal tunnel decompression on the referred patient. OSS, one-stop surgery.

participants in the long-term follow-up interview gave their informed consent prior to the interview.

\section{The patient flow from referral to discharge}

The neurosurgical department received referrals from general practitioners and neurologists. During the initial study period (2003-2007), all patients were offered an OSS appointment, as there was no preselection of patients for OSS. Later (2007-2009), we introduced preselection by a nurse-conducted telephone interview prior to the OSS appointment with the aim to screen out those patients unlikely to undergo OSS. Those patients were discharged directly from the telephone interview. In case of atypical presentation, inconclusive nerve conduction studies, pregnancy, history of relevant fractures or severe comorbidities, patients were offered a separate outpatient assessment instead of an OSS appointment before decision for surgery. Patient selected for OSS received written information about the procedure and an appointment. A diagram of the patient flow can be seen in figure 1 .

At the day of the OSS appointment, the surgeon performed a regular preassessment of the patient and, if indicated, performed surgery immediately afterwards. Patients were first operated on the side most affected. Patients with CTS in both hands, who had previously been operated with good symptom relief, were offered a new appointment for OSS on the opposite hand. During the study period (2003-2009), there was initially (2003-2005) no routine postoperative follow-up. Later (2006-2009), the outpatient nurse conducted postoperative follow-up by a telephone interview on day 1 and day 14 with the aim to identify postoperative complications requiring medical attention or guidance.

The standard surgical procedure was the endoscopic procedure with the single portal Wolf system. ${ }^{6}$ The surgery was performed with local infiltration anaesthesia with up to $10 \mathrm{~mL}$ of Marcain-Adrenalin (5 mg/ $\mathrm{mL}+5 \mathrm{ug} / \mathrm{mL}$ ) placed in the wrist and palm region without the use of a tourniquet. Open surgery was used in all reoperations and at the surgeon's individual choice, mostly in the case of severe compression with fixed neurological deficits and suspicion of a very narrow carpal tunnel. The surgeons were board certified neurosurgeons or trainees supervised by a board certified neurosurgeon.

\section{Outcome measures}

Primary outcome: residual symptoms

The 671 referred patients were evaluated by a structured telephone interview. Patients were first asked whether they had any residual symptoms at all. If the answer to this was 'yes', then specific enquiries were made about night-waking due to hand symptoms, hand weakness, aggravation of symptoms by hand activity, wrist pain and palm pain. Patients were also asked whether any of these symptoms were intermittent or continuous. 
Secondary outcomes: patient satisfaction scores and surgical complications

Patients were asked to assess the following on a 10-point scale ( $1=$ very unsatisfied, $10=$ verysatisfied) related to the effect of the surgery, the information level and the overall impression of the patient care and management.

The numbers and types of complications including suspected surgical site infections (SSIs) treated with antibiotics were recorded from the patient files and the longterm follow-up interviews.

The outcome measures were analysed in subgroups of (A) surgical technique (endoscopic, converted or a planned open procedure), (B) the surgeon and (C) patient characteristics as described in the demographic section. Six surgeons performed between 53 and 167 of the total 683 procedures. We pooled surgeons and supervised residents with less than 20 procedures in one group of total 52 procedures.

\section{Statistical analyses}

Data were organised in a relational database. The statistical analyses were performed post hoc using the IBM SPSS Statistics 24 software with multivariate logistic regression analysis analysed for each symptom independently with the specific (or none) symptom as the dependent and the following predictors: no risk factor, polyneuropathy, diabetes, connective tissue disease, metabolic disorder, arthrosis, symptoms $>3$ years, atrophy, excessive use of alcohol, age $>70$ and obesity. Each subgroup of patient satisfaction scores (1-10) were tested independently by two-sample t-test between the group of patients with no residual symptoms against each group of patients with a specific comorbidity. The level of statistical significance level $\left(\mathrm{p}_{\text {uncorrected }}\right)$ for the post hoc analysis was chosen at $\mathrm{p}<0.05(*), \mathrm{p}<0.01(* *)$ and $\mathrm{p}<0.001(* * *)$.

\section{RESULTS}

\section{Descriptive statistics of the cohort}

A large majority $(67 \%, \mathrm{n}=671)$ of the 1003 patients in the original cohort (2003-2009) completed the follow-up interview and constituted the study population. Of the 671 included patients, $507(78 \%)$ patients were discharged from the OSS clinic with surgery in one or both hands representing overall 683 carpal tunnel releases. An overview of the original cohort, the study population and the non-participants of both operated and non-operated patients can be seen in online supplementary material. Time from referral to follow-up was 56.5 months (15.3103.6). The average age was 55 years (21-97) for the operated patients with $77 \%$ being female and 53 years [26-89] for the non-operated patients with $73 \%$ being female.

The majority (93\%) of the operated patients had a neurophysiological evaluation. Patients referred without a neurophysiological evaluation were redirected for an electromyography (EMG) prior to the OSS appointment with the exception of distinct cases presenting a classical clinical picture and history of a successful operation on the opposite hand.

Relevant comorbidities for all patients in the follow-up study were polyneuropathy $(5 \%)$, metabolic disorder $(5 \%)$ primary myxoedema, connective tissue disease $(9 \%)$, diabetes $(14 \%)$, arthrosis and rheumatism $(21 \%)$, obesity (14\%) and excessive use of alcohol exceeding $14 / 21$ units per week for women/men (7\%). Other covariates were age above 70 years $(16 \%)$, use of translator $(1 \%)$, atrophy of the thenar $(7 \%)$ and duration of symptoms $>3$ years $(22 \%)$. Of the operated patients, $53 \%$ were on medication, which were true for $26 \%$ of the non-operated patients.

\section{Primary and secondary outcomes}

Good long-term symptom relief at follow-up

At time of follow-up, a vast majority of the operated patients had relief of symptoms, and $66 \%$ of the operated patients (table 1) became completely free of even minor symptoms compared with $37 \%$ of patients discharged without surgery (table 2). The average self-reported satisfaction score of the effect of surgery was 9.0 on a 1-10 scale. Patients with arthrosis, polyneuropathy or atrophy had less symptom relief as compared with patients with none or other comorbidities (tables 1 and 2).

The number of endoscopic, converted and primary open procedures are given in table 3. Reasons for conversion to open surgery were anatomical variations, insufficient space or pain during dissection or at the attempt to introduce the endoscopic guide tube. There was little difference in symptom relief between the endoscopic and the converted procedure. With the planned open procedure, however, which was conducted only in selected cases with severe neurological deficits and in reoperations, fewer patients experienced symptom relief (table 3).

Of the 164 patients discharged from the OSS clinic without surgery, $19(12 \%)$ were operated in another facility at a later stage. The 19 patients undergoing surgery in another facility after having been discharged from our clinic without surgery had at time of follow-up not improved when compared with the remaining 145 patients discharged without surgery who had never undertaken surgery at time of follow-up.

\section{COMPLICATIONS}

None of the 683 procedures resulted in severe complications. However, from review of patient journals in an additional 212 patients who did not complete or declined to participate in the follow-up interview, one patient developed reflex sympathetic dystrophy and another patient had damage to the recurrent muscular branch of the median nerve after surgery. The follow-up interviews did not reveal any complications unknown to the surgeons, except for a few patients treated with antibiotics for suspected SSIs (table 4).

The use of antibiotics for suspected SSI was 5\% and significantly higher for the converted procedure. The 


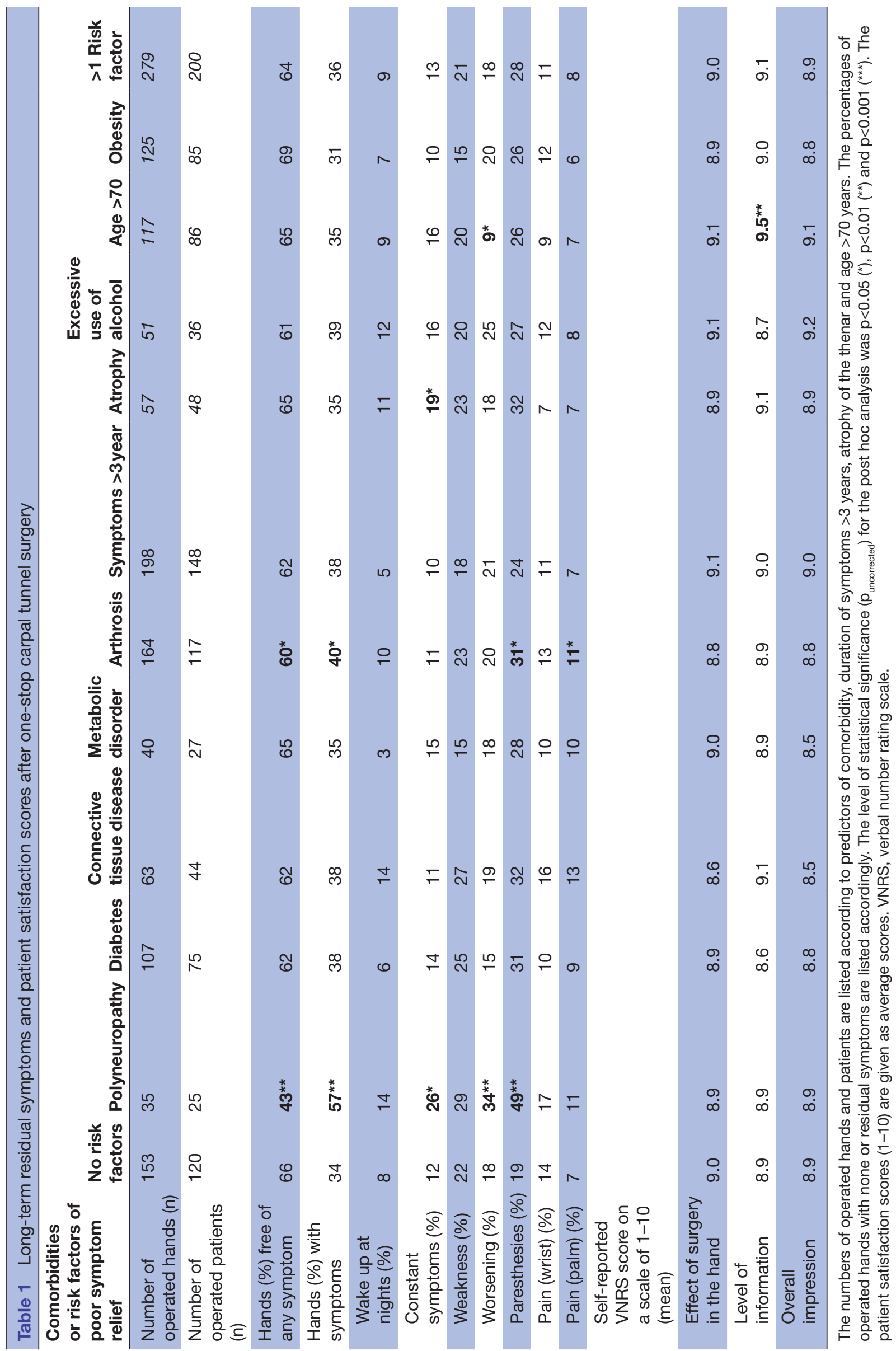




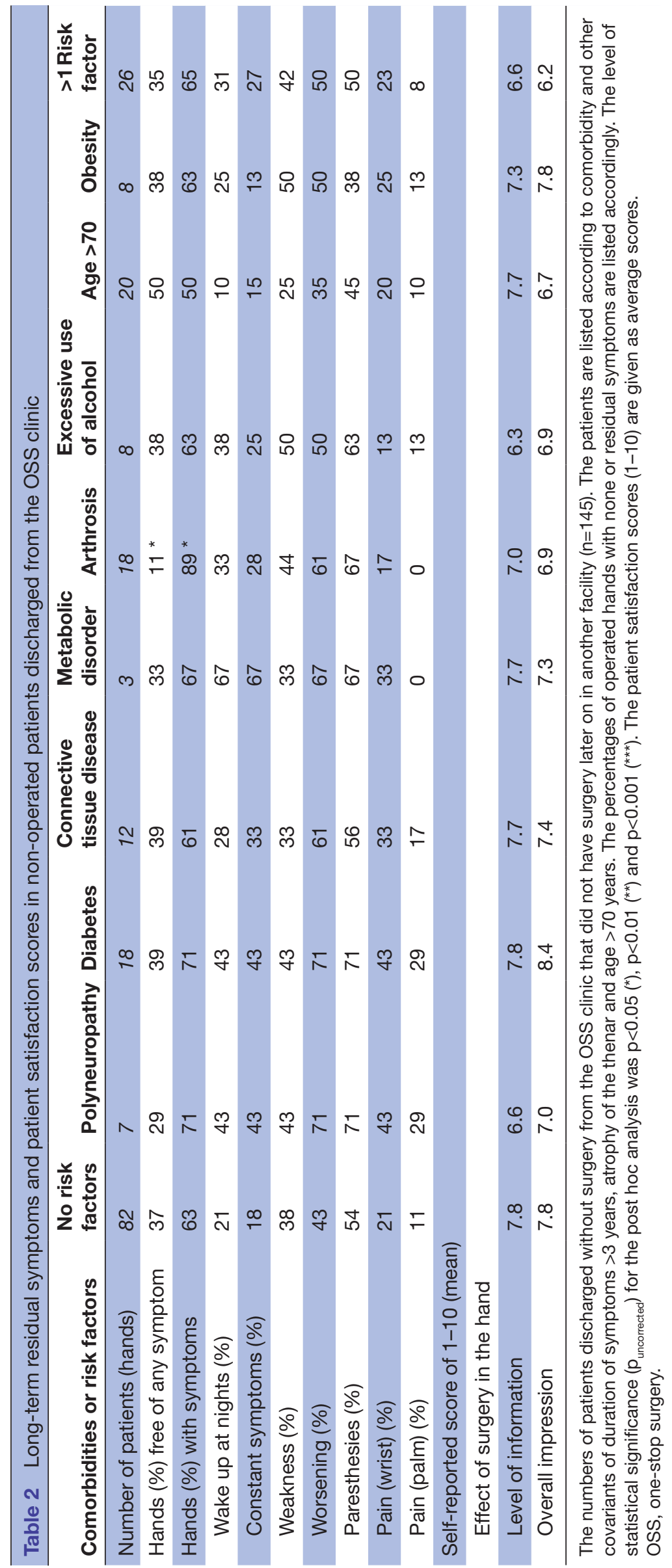


Table 3 Residual symptoms, effect score and SSI according to surgical technique

\begin{tabular}{|c|c|c|c|}
\hline & Endoscopic & Converted & $\begin{array}{l}\text { Primary } \\
\text { open }\end{array}$ \\
\hline & $\mathbf{n}$ & $\mathbf{n}$ & $\mathbf{n}$ \\
\hline $\begin{array}{l}\text { Number of operated } \\
\text { hands (patients) }\end{array}$ & 487 (366) & $140(108)$ & $56(33)$ \\
\hline $\begin{array}{l}\text { Hands (\%) free of any } \\
\text { symptom }\end{array}$ & 67 & 66 & $43^{\star \star \star}$ \\
\hline $\begin{array}{l}\text { Hands (\%) with } \\
\text { symptoms }\end{array}$ & 33 & 34 & $57^{\star \star \star}$ \\
\hline Wake up at nights (\%) & 6 & 8 & $29^{\star \star \star}$ \\
\hline $\begin{array}{l}\text { Constant symptoms } \\
(\%)\end{array}$ & 11 & 7 & $23^{\star \star}$ \\
\hline Weakness (\%) & 18 & 20 & $30^{\star}$ \\
\hline Worsening (\%) & 16 & 22 & $30^{\star \star}$ \\
\hline Paresthesies (\%) & 21 & 26 & $38^{\star \star}$ \\
\hline Pain (wrist) (\%)7 & 11 & 9 & $29^{\star \star \star}$ \\
\hline Pain (palm) (\%) & 7 & 7 & 13 \\
\hline \multicolumn{4}{|l|}{$\begin{array}{l}\text { Self-reported VNRS } \\
\text { score of } 1-10 \text { (mean) }\end{array}$} \\
\hline $\begin{array}{l}\text { Effect of surgery in } \\
\text { the hand }\end{array}$ & $8.9^{*}$ & 8.9 & $7.4^{\star \star \star}$ \\
\hline Level of information & 9.1 & 8.9 & 9.3 \\
\hline Overall impression & 9.1 & 8.9 & 8.9 \\
\hline
\end{tabular}

The numbers and percentages (\%) of operated hands with residual symptoms and self-reported scores (1-10) on a 10-point scale ( $1=$ very unsatisfied, $10=$ very satisfied) are listed according to surgical technique of the endoscopic, converted and planned open procedures. The level of statistical significance $\left(p_{\text {uncorrected }}\right)$ level was chosen at $\mathrm{p}<0.05\left(^{*}\right), \mathrm{p}<0.01{ }^{(*)}$ and $\mathrm{p}<0.001^{(* *)}$. The patient satisfaction scores (1-10) are given as the average mean score. SSI, surgical site infection; VNRS, verbal number rating scale.

rate of suspected SSI did not vary with patient age or gender but differed between surgeons $(1.3 \%-11.8 \%)$ and was significantly higher for two surgeons. Other complications did not relate to the surgical technique or a specific surgeon. Patients treated with antibiotics with or without microbiological confirmation of SSI were more likely to report residual symptoms at time of follow-up, but their self-reported satisfaction score of the effect of surgery (8.7) was not reduced as compared with patients not treated for SSI. Patients with complications other than SSI had significantly lower self-reported satisfaction score of the effect of surgery (6.3).

\section{DISCUSSION}

We have shown that OSS for CTS in our setting is safe and provides good long-term symptom relief and a high self-reported satisfaction score. The effectiveness of CTS is usually reported to be very high, although patients might still have some residual symptoms. Consistent with other studies of symptom relief after non-OSS, ${ }^{78}$ we
Table 4 Complications and reoperations

\begin{tabular}{lll}
\hline & No & $\%$ \\
\hline Procedures & 683 & \\
\hline Complications other than SSI & 16 & 2.3 \\
\hline $\begin{array}{l}\text { Excessive bleeding during surgery } \\
\text { Severe spasms (reschedule for }\end{array}$ & 1 & 0.1 \\
generalised anaesthesia) & 1 & 0.1 \\
$\quad$ Severe pain (admitted 24 hours) & 1 & 0.1 \\
\hline Reoperations & & \\
$\quad$ Postoperative haematoma & 1 & 0.1 \\
$\quad$ Deep infection & 3 & 0.4 \\
$\quad$ No effect or recurrence & 5 & 1.0 \\
\hline Worsening & 2 & 0.3 \\
$\quad$ Tenosynovitis & 1 & 0.1 \\
\hline$\quad$ Granuloma & 1 & 0.1 \\
\hline Antibiotic use (suspected superficial SSI) & 34 & 5.0 \\
\hline
\end{tabular}

The complications, reoperations and suspected superficial SSI are listed in all 683 procedures conducted in patients referred to the OSS clinic in the 7-year period 2003-2009 and included in the long-term follow-up interview.

OSS, one-stop surgery; SSI, surgical site infection.

found that two-thirds of patients were completely free of even minor residual or scar symptoms, and an additional group of patients benefitted from surgery to some extent. Non-operated patients had less symptom relief at longterm follow-up, which raises the concern that they could have been discharged in the presence of a CTS requiring surgery. However, the patients in this group who went on to have surgery in a later stage in another facility had no benefit compared with the patients who never had an operation, which does not support this assumption.

The results of CTS are often evaluated by physical findings, while patients might be more concerned about symptoms and functions, and symptom relief is the strongest predictor of satisfaction as compared with other outcome measures such as improvement of function. ${ }^{9} 10$ We demonstrate a good outcome with OSS for CTS in regard to symptom relief and high self-reported satisfaction scores. Others have demonstrated that patients with more severe symptoms and functional impairment assign higher importance to relief of symptoms, ${ }^{11}$ which is in line with the higher satisfaction scores in the operated patients observed in our study. A non-OSS follow-up consultation for patients discharged without surgery could potentially increase patient satisfaction and safety in this subgroup of patients.

Equivalent to others, ${ }^{312}$ we found good symptom relief in the elderly patients. The only factors significantly associated with poor outcome are polyneuropathy, arthrosis or atrophy of the thenar. Although diabetes, excessive alcohol use and age $>70$ years have previously been suggested to be poor prognostic factors, we did not find this. Therefore, in our OSS clinic, we perform surgery in 
the elderly and in patients with these comorbidities when otherwise relevant.

SSI was the most frequent complication, and the complication rate in the OSS clinic other than SSI was similar to that found in other studies. ${ }^{7813-19}$ Since SSI is the most frequent complication and major complications are rare, minor morbidities such as SSI may have a disproportionate impact on the perceived quality of care. ${ }^{20} 21$ The true incidence of infection is not clear since SSIs are evident only after the patient is discharged and rates derived from hospital records may be underestimates because of incomplete ascertainment. ${ }^{20} 22$ As in Atherton et $a l^{23}$ we believe that SSI is probably overdiagnosed and overtreated. In accordance with Harness $e t$ al, ${ }^{24}$ the higher infection rate did not differ significantly between genders.

We collected data from interviews by professionals related to the clinic, and recall bias represents a threat to the internal validity of this retrospective study, as it can be a challenge for the interviewed to recall the past. The risk of recall bias, however, can be reduced when the interviewer encourages the study participant to reflect and think through responses before answering. ${ }^{22}{ }^{25}$ Self-administered questionnaires generally result in a worse reported outcome than telephone interviews. ${ }^{26} 27$

Cochrane reviews did not favour the endoscopic technique or the open surgical technique. ${ }^{19} 28$ The complication rates in the OSS clinic other than SSI was similar to other studies. ${ }^{78}{ }^{13-19}$ In our OSS clinic, primary open surgery was conducted in cases of severe neurological impairment or reoperations, which could account for the less good symptom relief observed in our study with the planned open procedure. As in the study by Beck et $a l^{18}$ we did not find a difference in symptom relief between the converted and endoscopic procedure.

Our findings are applicable to outpatient clinics with surgical facilities. However, other one-stop clinics also include neurophysiological evaluations. Offering relevant neurophysiological evaluation, home kits and instructions for suture removals, resolvable stitches along with more strict preselection and improved information could provide a more genuine OSS service from the patient perspective and not as in our present practice, where the one-stop concept in reality mostly applies to the surgeon.

\section{CONCLUSIONS}

Increasing demands on the healthcare system call for exploration of new approaches to patient management. OSS can increase patient satisfaction and reduce medical and socioeconomic costs. We found that OSS is safe and associated with high self-reported satisfaction scores and a long-term symptom relief comparable with that of non-OSS patients. We recommend OSS as the standard procedure for surgical treatment of CTS.

Contributors LMJ contributed to the conception and design, data acquisition and analysis, and drafting of the manuscript. KP and KF contributed to the conception and design and provided substantial scientific contribution and critical revision of important intellectual content. AB, MBL, PSP and SB contributed to the acquisition of data. All authors have reviewed the manuscript critically and approved the final manuscript.

Funding The study was supported with Kr20 000 (approximately €2700) from a fund donated to the department by a former patient. The funding was primarily spent on administrative assistance of retrieving phone numbers and addresses for the patients and sending out letters. The authors did not receive money or benefits. Competing interests None declared.

Patient consent Obtained.

Ethics approval The study was approved by the Data Protection Agency file \# 2011-41-6315, and informed consent prior to the interview was obtained.

Provenance and peer review Not commissioned; externally peer reviewed.

Data sharing statement All data from the present study can be obtained upon request to the corresponding author.

Open Access This is an Open Access article distributed in accordance with the Creative Commons Attribution Non Commercial (CC BY-NC 4.0) license, which permits others to distribute, remix, adapt, build upon this work non-commercially, and license their derivative works on different terms, provided the original work is properly cited and the use is non-commercial. See: http://creativecommons.org/ licenses/by-nc/4.0/

(c) Article author(s) (or their employer(s) unless otherwise stated in the text of the article) 2017. All rights reserved. No commercial use is permitted unless otherwise expressly granted.

\section{REFERENCES}

1. Atroshi I, Englund M, Turkiewicz A, et al. Incidence of physiciandiagnosed carpal tunnel syndrome in the general population. Arch Intern Med 2011;171:941-54.

2. Korthals-de Bos IB, Gerritsen AA, van Tulder MW, et al. Surgery is more cost-effective than splinting for carpal tunnel syndrome in the Netherlands: results of an economic evaluation alongside a randomized controlled trial. BMC Musculoskelet Disord 2006;7:86.

3. Jarrett ME, Giddins GE. Direct access carpal tunnel surgery. J Bone Joint Surg Br 2003;85:B:869-70.

4. Ball C, Pearse M, Kennedy D, et al. Validation of a one-stop carpal tunnel clinic including nerve conduction studies and hand therapy. Ann R Coll Surg Engl 2011;93:634-8.

5. Reid M, David L. Nicholl J. A One-Stop Carpal Tunnel Clinic. Ann R Coll Surg Engl 2009;91:301-4.

6. Richard Wolf GmbH. Endoscopic carpal tunnel release - The "ENDOCARTRIS" instrument set. http://www.richard-wolf.com/discipline/ orthopedics/applications-and-methods/endoscopic-decompressionof-peripheral-nerves.html (accessed 5 Jan 2015).

7. DeStefano F, Nordstrom DL, Vierkant RA. Long-term symptom outcomes of carpal tunnel syndrome and its treatment. $J$ Hand Surg Am 1997;22:200-10.

8. Lindau T, Karlsson MK. Complications and outcome in open carpal tunnel release. A 6-year follow-up in 92 patients. Chir Main 1999;18:115-21.

9. Levine DW, Simmons BP, Koris MJ, et al. A self-administered questionnaire for the assessment of severity of symptoms and functional status in carpal tunnel syndrome. J Bone Joint Surg Am 1993;75:1585-92.

10. Kadzielski J, Malhotra LR, Zurakowski D, et al. Evaluation of preoperative expectations and patient satisfaction after carpal tunnel release. J Hand Surg Am 2008;33:1783-8.

11. Bessette L, Keller RB, Liang MH, et al. Patients' preferences and their relationship with satisfaction following carpal tunnel release. $J$ Hand Surg Am 1997;22:613-20.

12. Townshend DN, Taylor PK, Gwynne-Jones DP. The outcome of carpal tunnel decompression in elderly patients. J Hand Surg Am 2005;30:500-5.

13. Hanssen AD, Amadio PC, DeSilva SP, et al. Deep postoperative wound infection after carpal tunnel release. J Hand Surg Am 1989;14:869-73.

14. Brown MG, Rothenberg ES, Keyser B, et al. Results of 1236 endoscopic carpal tunnel release procedures using the Brown technique. Contemp Orthop 1993;27:251-8.

15. Concannon MJ, Brownfield ML, Puckett CL. The incidence of recurrence after endoscopic carpal tunnel release. Plast Reconstr Surg 2000;105:1662-5. 
16. McNally SA, Hales PF. Results of 1245 endoscopic carpal tunnel decompressions. Hand Surg 2003;8:111-6.

17. Atroshi I, Hofer M, Larsson GU, et al. Open compared with 2-portal endoscopic carpal tunnel release: a 5-year follow-up of a randomized controlled trial. J Hand Surg Am 2009;34:266-72.

18. Beck JD, Deegan JH, Rhoades D, et al. Results of endoscopic carpal tunnel release relative to surgeon experience with the Agee technique. J Hand Surg Am 2011;36:61-4.

19. Vasiliadis HS, Georgoulas P, Shrier I, et al. Endoscopic release for carpal tunnel syndrome. Cochrane Database Syst Rev 2014;1:CD008265.

20. Brown RB, Bradley S, Opitz E, et al. Surgical wound infections documented after hospital discharge. Am J Infect Control 1987;15:54-8.

21. Brebbia G, Boni L, Dionigi G, et al. Surgical site infections in day surgery settings. Surg Infect 2006;7:121-123.

22. Atherton WG, Faraj AA, Riddick AC, et al. Follow-up after carpal tunnel decompression - general practitioner surgery or hand clinic? A randomized prospective study. J Hand Surg Br 1999;24:296-7.
23. Harness NG, Inacio MC, Pfeil FF, et al. Rate of infection after carpal tunnel release surgery and effect of antibiotic prophylaxis. $J$ Hand Surg Am 2010;35:189-96.

24. Bradburn NM, Rips LJ, Shevell SK. Answering autobiographical questions: the impact of memory and inference on surveys. Science 1987;236:157-61.

25. Althubaiti A. Information bias in health research: definition, pitfalls, and adjustment methods. J Multidiscip Healthc 2016;9:211-7.

26. Höher J, Bach T, Münster A, et al. Does the mode of data collection change results in a subjective knee score? Self-administration versus interview. Am J Sports Med 1997;25:642-7.

27. Bowling $A$. Mode of questionnaire administration can have serious effects on data quality. J Public Health 2005;27:281-91.

28. Scholten RJ, Mink van der Molen A, Uitdehaag BM, et al. Surgical treatment options for carpal tunnel syndrome. Cochrane Database of Systematic Reviews: John Wiley \& Sons, Ltd, 1996. 